'Instituto Agronômico de Pernambuco (IPA), Av. General San Martin, 1371, Bongi, CEP 50761-000, Recife, PE, Brasil

*autor correspondente \servulo.siqueira@ipa.br

\title{
Comportamento de cultivares de girassol em condições de sequeiro no estado de Pernambuco
}

\author{
Sunflower cultivars behaviour in dry condition in \\ Pernambuco state
}

Sérvulo Mercier Siqueira e Silva ${ }^{*}$, Ivan Souto de Oliveira Júnior ${ }^{1}$, Farnésio de Sousa Cavalcante ${ }^{1}$, José Alves Tavares ${ }^{1}$, José Nunes Filho'

RESUMO: O girassol vem sendo amplamente cultivado no país para a indústria alimentícia, além de se destacar como cultura promissora, capaz de fomentar diversos programas, como o do Biodiesel no Brasil. O presente trabalho teve como objetivo selecionar cultivares de girassol que apresentem melhor desempenho produtivo no Estado de Pernambuco. A pesquisa foi desenvolvida no ano de 2011 nas cidades de Araripina, Caruaru e Serra Talhada. O delineamento estatístico adotado no estudo foi de blocos ao acaso, sendo dez genótipos de girassol; M 734-T, Embrapa 122-T, Aromo 10, Paraíso 22, Albisol $20 \mathrm{CL}$, NTO 2.0, Multissol, V50070, Triton Max e Gira 27 , com quatro repetições. Foi realizado um teste de comparação de média em cada localidade, além da análise conjunta dos dados. Os materiais avaliados obtiveram bom desempenho em condições de sequeiro, com precipitações em torno de $550 \mathrm{~mm}$ no ciclo da cultura, indicando o girassol como uma boa opção de cultivo para o Semiárido pernambucano. A produtividade média em torno de $1.700 \mathrm{~kg} \cdot$ ha $^{-1}$ entre as regiões estudadas favorece o cultivo de alguns genótipos de girassol para Pernambuco.

PALAVRAS-CHAVE: Helianthus annuus, semiárido, adaptabilidade.
ABSTRACT: Sunflower has been widely cultivated in the country for the food industry, as well as being a promising crop, capable of promoting several programs such as Biodiesel in Brazil. The present work had the objective to select sunflower cultivars with better productive performance in Pernambuco State. The research was developed in 2011 in the cities of Araripina, Caruaru and Serra Talhada. The statistical design adopted in the study was of randomized blocks, with ten sunflower genotypes; M 734-T, Embrapa 122-T, Aromo 10, Paraíso 22, Albisol 20 CL, NTO 2.0, Multisol, V50070, Triton Max and Gira 27, with four repetitions. A test of comparison of averages was performed at each location, besides the joint analysis of the data. The evaluated materials obtained good performance in dry conditions, with precipitations around $550 \mathrm{~mm}$ in the crop cycle, indicating that the sunflower as a good cultivation option for the semiarid of Pernambuco. The average yield of around 1,700 kg. ha-1 among the studied regions favors the cultivation of some sunflower genotypes for Pernambuco.

KEYWORDS: Helianthus annuus, semiarid, adaptability.

\section{Introdução}

A cultura do girassol (Helianthus annuиs, L.) tem despertado interesse em todo o mundo em virtude da sua reconhecida importância socioeconômica, destacando-se como a quinta maior oleaginosa em produção de grãos, quarta em produção de farelo e terceira em produção mundial de óleo (GAZZOLA et al., 2012).

O Brasil, apesar de apresentar enorme potencial produtivo, não se destaca como um dos grandes produtores, entretanto, $\mathrm{o}$ 
girassol vem sendo largamente cultivado no país, objetivando o fornecimento de matéria-prima para a indústria alimentícia, além de se destacar como cultura promissora, capaz de fomentar diversos programas como o do Biodiesel no Brasil (NOBRE et. al., 2010), (SANTOS JUNIOR et al., 2011), (JUNIOR et al., 2013) e (SILVA, 2014).

De acordo com a CONAB (2018), a área estimada para plantio na safra 2017/2018 foi 97 mil ha para uma produção estimada de 148,6 mil t. Nos últimos registros para a Região Nordeste, verifica-se que o estado que se destacou tendo a maior área plantada com a cultura foi a Bahia, com 0,3 mil hectares, e em relação à produtividade, o destaque foi para o Ceará, com 456 kg.ha-1 (CONAB, 2013).

Em Pernambuco, os dados referentes à cultura do girassol ainda são incipientes e restringem-se a resultados de pesquisas realizadas pelo Instituto Agronômico de Pernambuco (IPA). Segundo Cavalcante et al. (2010), Silva et al., (2011) e Oliveira Junior et al. (2011), alguns materiais obtiveram produtividades superiores a $2.000 \mathrm{~kg}$.ha ${ }^{-1} \mathrm{em}$ cultivo de sequeiro, com precipitação de aproximadamente $600 \mathrm{~mm}$, durante o ciclo da cultura.

Elevadas produtividades médias têm sido utilizadas como critério de recomendação de materiais avaliados, no entanto, este critério pode prejudicar ou beneficiar genótipos com adaptação específica a determinados tipos de ambientes (MENEZES et al., 2011). Devido à existência da interação genótipo $\mathrm{x}$ ambiente, faz-se necessário a avaliação contínua dos genótipos em rede de ensaios, visando o conhecimento do seu comportamento agronômico e de sua adaptação às condições edafoclimáticas das áreas produtoras (PORTO et al., 2007) e (CARVALHO 2015). Além do alto rendimento de grãos e da maior adaptação, outros aspectos desejáveis devem ser avaliados para o desenvolvimento de cultivar de girassol, como percentual de óleo, precocidade, dentre outras.

Por ser o girassol uma cultura mais tolerante à seca, ao frio e ao calor do que a maioria das espécies cultivadas no Brasil, existem plantios em várias regiões sem a devida comprovação de viabilidade técnica e econômica, ignorando-se que ocorre interação entre genótipos e ambientes, sendo, portanto, imprescindível a pesquisa contínua de adaptação dessa oleaginosa em várias regiões (BACKES et al., 2008).

Com base nas informações descritas, objetivou-se com o presente trabalho selecionar cultivares ou híbridos de girassol que proporcionem bom desempenho produtivo para as condições do Semiárido de Pernambuco.

\section{Material e Métodos}

A pesquisa foi desenvolvida com o girassol (Helianthus annuus L.) nas Estações Experimentais do IPA localizadas nos municípios de Araripina, Caruaru e Serra Talhada no Estado de Pernambuco, no ano de 2011. As localizações e caracterizações das áreas estão dispostas na Tabela 1. Os experimentos foram conduzidos em regime de sequeiro de acordo com a Figura 1.

Foram utilizadas as mesmas práticas para o preparo do solo em todas as áreas, as quais constaram de uma aração seguida de uma gradagem. Os plantios foram feitos em covas com duas sementes, levando em consideração o melhor período de chuvas para cada região e adubação conforme análise química do solo. Em todas as localidades foi aplicada adubação com $2,0 \mathrm{~kg}$ de boro, tendo como fonte o ácido bórico.

Cada parcela experimental foi constituída de três fileiras de $6 \mathrm{~m}$ de comprimento e utilizada como área útil a fileira central. O espaçamento utilizado foi de $0,7 \mathrm{~m} \times 0,3 \mathrm{~m}$, totalizando 21 plantas/fileira. O desbaste foi efetuado aos 15 dias após a germinação, deixando-se uma planta/cova. O controle das plantas invasoras foi realizado através de capina manual com o uso da enxada, observando-se o período crítico de ocorrência.

Foram avaliadas as seguintes variáveis: floração inicial (FI) (dias), dias para maturação fisiológica do capítulo (DM) (dias), altura de planta (AP) $(\mathrm{cm})$, tamanho do capítulo $(\mathrm{TC})(\mathrm{cm})$, peso de mil aquênios (PMA) (g) e produtividade (Prod) (kg.ha-1).

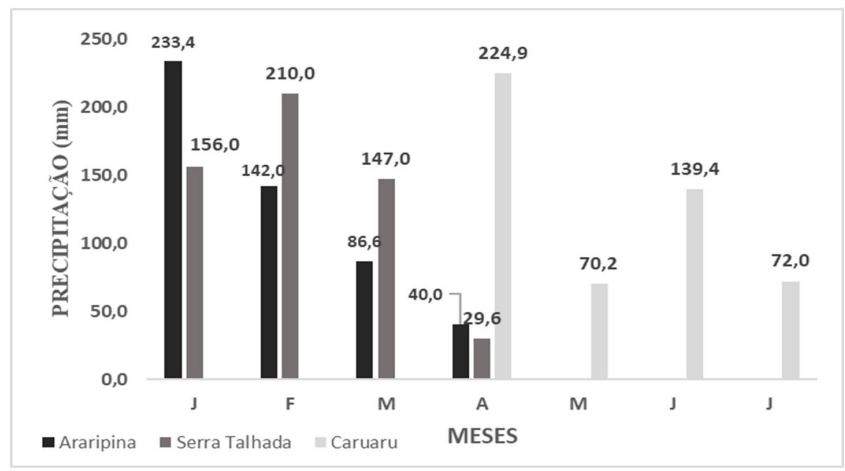

Figura 1. Precipitação durante o ciclo de cultivo do girassol nos municípios de Araripina, Serra Talhada e Caruaru, 2011.

Tabela 1. Caracterização das áreas experimentais nos municípios de Araripina, Caruaru e Serra Talhada, 2011.

\begin{tabular}{|c|c|c|c|}
\hline $\begin{array}{c}\text { CARACTERÍSTICAS } \\
\text { DAS ÁREAS }\end{array}$ & ARARIPINA & CARUARU & SERRA TALHADA \\
\hline MICRORREGIÃO & Araripe & Agreste Central & Pajeú \\
\hline LATITUDE & $07^{\circ} 34^{\prime} 34^{\prime \prime} \mathrm{S}$ & $08^{\circ} 01 ' 18^{\prime} \mathrm{S}$ & $07^{\circ} 56,58,59 " \mathrm{~S}$ \\
\hline LONGITUDE & $40^{\circ} 29,54 \% \mathrm{~W}$ & $36^{\circ} 00^{\prime} 00^{\prime \prime} \mathrm{W}$ & $38^{\circ} 11 ' 41,30^{\prime}$ W \\
\hline ALTITUDE & $750 \mathrm{~m}$ & $537 \mathrm{~m}$ & $506 \mathrm{~m}$ \\
\hline PRECIPITAÇÃO & $502,0 \mathrm{~mm}$ & $507,3 \mathrm{~mm}$ & $542,6 \mathrm{~mm}$ \\
\hline CLIMA & BSh & BSh & BSh \\
\hline TIPO DE SOLO & Latassolo vermelho amarelo distrófico & Neossolo regolítico & Cambissolo \\
\hline
\end{tabular}

BSh (clima semiárido quente). 
O delineamento estatístico adotado no estudo foi de blocos ao acaso, com quatro repetições, onde foram utilizados dez genótipos de girassol: M 734-T, Embrapa 122-T, Aromo 10, Paraíso 22, Albisol 20 CL, NTO 2.0, Multissol, V50070, Triton Max e Gira 27. Os dados foram analisados para cada localidade e em grupos de experimentos seguindo a metodologia de CANTERI et al. (2001), para verificar o comportamento do girassol entre as localidades. Para efeito de comparação de médias, foi aplicado o Teste de Tukey a $5 \%$.

\section{Resultados e Discussão}

As precipitações ocorridas durante o ciclo da cultura em 2011 foram de 502,0, 506,5 e 542,6 mm para Araripina, Caruaru e Serra Talhada, respectivamente. Dentro das necessidades hídricas do girassol, que são em torno de 400 a $600 \mathrm{~mm}$ (GAZZOLA et al., 2012).

A variação da disponibilidade hídrica do solo influencia no desenvolvimento da cultura do girassol, levando a diferentes respostas. Dentre elas, Saensee et al. (2012) verificaram que em regiões com baixa disponibilidade hídrica o girassol diminui consideravelmente todos os seus atributos, prejudicando a avaliação de variáveis de crescimento, desenvolvimento e produção.

Para Silva et al. (2007) e Andrade et al. (2011), há estreita relação entre a variação da disponibilidade de água na irrigação e a produtividade nesta cultura. Enquanto para Merrien e Milan (1992) o girassol não apresenta regulação adequada em relação ao consumo de água, extraindo quantidades consideráveis do solo, devido à baixa resistência à difusão de água pelos os estômatos, em razão destes serem grandes e numerosos, principalmente na face inferior do limbo. Para os referidos autores, o girassol apresenta uma tendência de despediçar a água quando ela é oferecida em abundância.

Abaixo, na tabela 2, tem-se o resumo da análise de variância do estudo, onde se verifica que houve efeito significativo nas variáveis altura de planta e produtividade no fator Local (A), enquanto para as Cultivares (B) houve efeito significativo ao nível de $(\mathrm{p}<0,05)$ para todas as variáveis. Na interação (A x B), apenas não houve diferença estatística no peso de mil aquênios (PMA).

Tabela 2. Resumo da análise de variância referente à Floração Inicial (FI), Dias para Maturação (DM), Altura de Plantas (AP), Tamanho do Capítulo (TC), Peso de Mil Aquênios (PMA) e Produtividade (Prod) de genótipos de girassol cultivados em diferentes localidades no Estado de Pernambuco, 2011.

\begin{tabular}{|c|c|c|c|c|c|c|c|}
\hline \multirow{2}{*}{$\begin{array}{c}\text { Fonte } \\
\text { Variação }\end{array}$} & \multicolumn{7}{|c|}{ Quadrados Médios } \\
\hline & GL & FI & DM & AP & TC & PMA & Prod \\
\hline Locais (A) & 02 & $744,26 * *$ & $3913,27 * *$ & $1912,13^{\mathrm{ns}}$ & $462,66 * *$ & $2414,86 * *$ & $1253565,4^{\text {ns }}$ \\
\hline Cultivares (B) & 09 & $85,52 * *$ & $32,09 * *$ & $178,33 * *$ & $13,53 * *$ & $545,24 * *$ & $301040,3 * *$ \\
\hline Int. (A x B) & 18 & $21,20 * *$ & $10,58 * *$ & $250,79 * *$ & $7,07 * *$ & $61,85^{\text {ns }}$ & $267181,7 * *$ \\
\hline Tratamento & 29 & 91,03 & 286,41 & 342,88 & 40,49 & 374,15 & 345716,0 \\
\hline Blocos & 9 & 37,62 & 0,39 & 570,23 & 8,79 & 49,94 & 707166,8 \\
\hline Res. Médio & 81 & 6,02 & 1,60 & 101,61 & 2,79 & 55,58 & 108268,9 \\
\hline $\mathrm{CV}$ & & 4,31 & 1,38 & 7,48 & 8,37 & 10,38 & 19,44 \\
\hline
\end{tabular}

significativo a $0,05(*)$ e a $0,01(* *)$ de probabilidade; ${ }^{\text {ns }}$ não significativo.

Tabela 3. Médias dos Dias para Floração Inicial (FI) de genótipos de girassol, cultivados em diferentes localidades no Estado de Pernambuco, 2011.

\begin{tabular}{|c|c|c|c|}
\hline \multirow{2}{*}{ GENÓTIPOS } & \multicolumn{3}{|c|}{ Dias para Floração Inicial (dias) } \\
\hline & Araripina & Caruaru & Serra Talhada \\
\hline 1 - M 734-T & $61,00 \mathrm{a} A$ & $62,00 \mathrm{a} A$ & 53,50ab B \\
\hline 2 - Embrapa 122-T & $53,00 \mathrm{cA}$ & $54,50 \mathrm{c} \mathrm{A}$ & $48,00 b$ B \\
\hline 3 - Aromo 10 & $63,00 \mathrm{a} A$ & $61,50 \mathrm{ab} A$ & $53,25 a b$ B \\
\hline 4 - Paraiso 22 & 55,00 bc B & $60,75 \mathrm{ab} A$ & 50,50ab C \\
\hline 5 - Albisol 20 CL & $60,00 a b \mathrm{~A}$ & $60,75 \mathrm{ab} A$ & 53,50ab B \\
\hline 6 - NTO 2.0 & $60,00 a b \mathrm{~A}$ & 58,50 abcA & 50,25ab B \\
\hline 7 - Multissol & $60,00 a b A$ & $56,25 \mathrm{bc} \mathrm{A}$ & 51,75ab B \\
\hline 8 - V50070 & $63,00 a \mathrm{~A}$ & $63,50 a \mathrm{~A}$ & 54,75 a B \\
\hline 9 - Triton $\max$ & $60,00 \mathrm{ab} A$ & $64,00 a \mathrm{~A}$ & $52,00 a b$ B \\
\hline 10 - BRS Gira 27 & 50,00 c B & 59,50abcA & $52,25 a b \mathrm{AB}$ \\
\hline
\end{tabular}

Médias seguidas pela mesma letra minúscula nas colunas e maiúsculas nas linhas não diferem as cultivares dentro da localidade e entre as localidades, respectivamente, pelo teste de Tukey ao nível de $5 \%$ de probabilidade. 
Na Tabela 3 houve diferenciação estatística no número de dias para a floração inicial entre as localidades. De modo geral, os valores encontrados em Araripina se aproximam dos valores de Caruaru e ambos têm a floração mais tardia quando comparadas àquelas obtidas em Serra Talhada.

O girassol Embrapa 122-T, em Serra Talhada, obteve média de 48 dias para floração após a semeadura, e foi o mais precoce no estudo, embora não tenha sido diferenciado estatisticamente de outros genótipos. Este material também se comportou como o mais precoce em Caruaru, com 54 dias, e um dos primeiros a florescer em Araripina, com 53 dias. Esses resultados se aproximam aos obtidos por Aquino et al. (2013), com 51 dias, porém em condições irrigadas. Já Andrade et al. (2011) constataram que o genótipo Embrapa 122-T, em cultivo irrigado em Sousa-PB, também teve sua floração antecipada, com cerca de dez dias, em relação àqueles demais genótipos estudados.

Especificamente sobre o V50070, este foi o mais tardio nas três localidades, embora não diferindo estatisticamente de outros materiais, e em Araripina ele floresceu em média 13 dias após o BRS Gira 27.

Por meio do estudo, observa-se um grande intervalo de dias para as florações entre os genótipos, onde se permite inferir que não são exclusivamente as condições climáticas (precipitações, temperatura, umidade relativa, radiação, etc.) que influenciam essa característica da planta, mas também uma variabilidade genética intrínseca a cada material.

Essas premissas corroboram Nobre et al. (2012), que observaram que a floração inicial do girassol pode estar mais relacionada ao potencial de cada genótipo do que às condições climatológicas, uma vez que em resultados de pesquisas considerando datas e duração do período de floração, foram encontradas variações relacionadas às variedades estudadas.

$\mathrm{Na}$ Tabela 4 estão as médias dos dias para maturação fisiológica do capítulo (DM) dos genótipos de girassol. Analisando em cada local, verifica-se que houve diferença estatística entre os genótipos nas três localidades, com Serra Talhada tendo a maturação do capítulo ocorrido em menor espaço de tempo.

De modo geral, todos os genótipos de girassol submetidos às condições edafoclimáticas do Semiárido brasileiro tendem a completar o seu ciclo fisiológico mais precocemente, devido à temperatura e insolação médias diárias elevadas nessa região, indicando mecanismos de defesa das plantas em sua adaptabilidade ao clima e ao ambiente.

Os resultados de Serra Talhada foram em média 20 dias mais precoces que os de Caruaru, enquanto estes obtiveram valores muito próximos aos encontrados em Araripina. Assim como ocorreu na (FI), o genótipo Embrapa 122-T seguiu a mesma coerência e foi o genótipo com maturação fisiológica mais precoce em Serra Talhada, Caruaru e Araripina, sugerindo uma relação intrínseca entre estas variáveis.

É bom estar atento, pois a maturação mais cedo pode comprometer o crescimento do capítulo, o peso dos grãos e interferir diretamente na produtividade. Ungaro et al. (2000) afirmam que em geral há uma tendência de algumas cultivares de girassol com maturação tardia obterem maiores índices de produtividades, porque esses materiais têm maior tempo para realizar a fotossíntese, o que resulta em maior produção de matéria seca.

Outra variável estudada foi a AP, na qual se observa que apenas em Serra Talhada há diferenciação estatística entre os genótipos, quando analisado em cada local, onde o girassol V50070 e o M 734-T obtiveram as menores AP com cerca de $22,17 \%$ mais baixo que o Multissol (Tabela 5). Nas outras localidades, genótipos específicos tiveram menores AP, como é o caso do BRS Gira 27 em Araripina e o do Triton Max em Caruaru.

Entre as localidades, o Multissol de Serra Talhada foi superior em $10,44 \%$ e $23,45 \%$ às plantas do mesmo material em Caruaru e Araripina, respectivamente. Para Fagundes et al. (2007), no processo de crescimento de uma cultura ocorrem incrementos na massa, volume, comprimento, altura média e área foliar,

Tabela 4. Médias dos Dias para Maturação Fisiológica do Capítulo (DM) de genótipos de girassol, cultivados em diferentes localidades no Estado de Pernambuco, 2011.

\begin{tabular}{|c|c|c|c|}
\hline \multirow{2}{*}{ GENÓTIPOS } & \multicolumn{3}{|c|}{ Dias para Maturação Fisiológica (dias) } \\
\hline & Araripina & Caruaru & Serra Talhada \\
\hline 1 - M 734-T & $96,00 \mathrm{a} A$ & 97,25de A & $81,75 \mathrm{abcB}$ \\
\hline 2 - Embrapa 122-T & 92,00b B & $96,25 \mathrm{e} A$ & 77,00d C \\
\hline 3 - Aromo 10 & $96,00 a$ B & $98,75 \mathrm{cdeA}$ & $81,75 a b c C$ \\
\hline 4 - Paraiso 22 & $92,00 b$ B & 99,50bcdA & $79,25 \mathrm{~cd} \mathrm{C}$ \\
\hline 5 - Albisol 20 CL & $95,00 \mathrm{a} B$ & $105,25 \mathrm{aA}$ & $82,25 a b \mathrm{C}$ \\
\hline 6 - NTO 2.0 & 95,00 a B & $98,75 \mathrm{cdeA}$ & 78,75cd C \\
\hline 7 - Multissol & 95,00 a B & $102,25 b \mathrm{~A}$ & $80,50 b c$ C \\
\hline 8 - V50070 & $96,00 a$ B & $100,25 \mathrm{bcA}$ & $84,00 \mathrm{a} \mathrm{C}$ \\
\hline 9 - Triton max & $95,00 a$ B & $100,50 \mathrm{bcA}$ & $80,25 b c \mathrm{C}$ \\
\hline 10 - BRS Gira 27 & $92,00 b$ B & 100,00 bcdA & 81,25abc C \\
\hline
\end{tabular}

Médias seguidas pela mesma letra minúscula nas colunas e maiúsculas nas linhas não diferem as cultivares dentro da localidade e entre as localidades, respectivamente, pelo teste de Tukey ao nível de $5 \%$ de probabilidade. 
Tabela 5. Médias da Altura da Planta (AP), de genótipos de girassol, cultivados em diferentes localidades no Estado de Pernambuco, 2011.

\begin{tabular}{|c|c|c|c|}
\hline \multirow{2}{*}{ GENÓTIPOS } & \multicolumn{3}{|c|}{ Altura da Planta (cm) } \\
\hline & Araripina & Caruaru & Serra Talhada \\
\hline 1 - M 734-T & $126,25 \mathrm{a} B$ & $145,75 \mathrm{aA}$ & $125,50 \mathrm{~b} B$ \\
\hline 2 - Embrapa 122-T & $126,75 \mathrm{a} \mathrm{A}$ & $132,50 a \mathrm{~A}$ & $131,75 b \mathrm{~A}$ \\
\hline 3 - Aromo 10 & 123,25 a B & $141,50 \mathrm{a} A \mathrm{~B}$ & $147,25 \mathrm{abA}$ \\
\hline 4 - Paraiso 22 & 126,75 a B & $144,25 \mathrm{a} A$ & 141,50abAB \\
\hline 5 - Albisol 20 CL & $123,00 \mathrm{a} B$ & $137,50 a \mathrm{AB}$ & $146,50 \mathrm{abA}$ \\
\hline 6 - NTO 2.0 & $131,25 \mathrm{a} A$ & $134,25 \mathrm{aA}$ & $135,50 \mathrm{~b} A$ \\
\hline 7 - Multissol & 130,75a B & $137,00 a$ B & $161,25 \mathrm{aA}$ \\
\hline 8 - V50070 & $130,50 a \mathrm{AB}$ & $146,00 \mathrm{a} A$ & $125,50 \mathrm{~b}$ B \\
\hline 9 - Triton max & $129,50 a \mathrm{~A}$ & $129,50 \mathrm{aA}$ & $144,00 \mathrm{a} A$ \\
\hline 10 - BRS Gira 27 & $120,50 \mathrm{a} A$ & $135,25 a \mathrm{~A}$ & $133,75 b \mathrm{~A}$ \\
\hline
\end{tabular}

Médias seguidas pela mesma letra minúscula nas colunas e maiúsculas nas linhas não diferem as cultivares dentro da localidade e entre as localidades, respectivamente, pelo teste de Tukey ao nível de 5\% de probabilidade.

Tabela 6. Médias do Tamanho de Capítulo (TC) de genótipos de girassol, cultivados em diferentes localidades no Estado de Pernambuco, 2011.

\begin{tabular}{|c|c|c|c|}
\hline \multirow{2}{*}{ GENÓTIPOS } & \multicolumn{3}{|c|}{ Tamanho de Capítulo (cm) } \\
\hline & Araripina & Caruaru & Serra Talhada \\
\hline 1 - M 734-T & $18,88 b c$ B & 24,13ab A & $15,50 a \mathrm{C}$ \\
\hline 2 - Embrapa 122-T & $18,93 \mathrm{bc} A$ & 21,75b A & $16,00 \mathrm{a} B$ \\
\hline 3 - Aromo 10 & 20,28abc B & 23,38ab A & $16,25 \mathrm{a} \mathrm{C}$ \\
\hline 4 - Paraiso 22 & 21,40abc A & 23,00ab A & $16,00 \mathrm{a} C$ \\
\hline 5 - Albisol 20 CL & 22,73ab A & 23,13ab A & 18,25 a C \\
\hline 6 - NTO 2.0 & $23,25 a A$ & $23,00 a b \mathrm{~A}$ & 16,50a B \\
\hline 7 - Multissol & 19,45abc AB & $21,25 b \mathrm{~A}$ & 17,25 a B \\
\hline 8 - V50070 & 23,30a A & $25,75 \mathrm{a} \mathrm{A}$ & $15,50 a$ B \\
\hline 9 - Triton max & $18,90 \mathrm{bc} B$ & 24,25ab A & 16,25 a B \\
\hline 10 - BRS Gira 27 & $17,93 \mathrm{c} \mathrm{B}$ & $21,00 \mathrm{~b} A$ & $15,75 a \mathrm{~B}$ \\
\hline
\end{tabular}

Médias seguidas pela mesma letra minúscula nas colunas e maiúsculas nas linhas não diferem as cultivares dentro da localidade e entre as localidades, respectivamente, pelo teste de Tukey ao nível de $5 \%$ de probabilidade.

sendo isso resultados de fatores genéticos e ambientais. Esses fatores justificam a avaliação do porte de cada material, visando uma colheita mais uniforme.

Smiderle et al. (2005) ressaltam que o girassol possui um período inicial de crescimento lento, mas em seguida acelera e chega a atingir de $90-95 \%$ da altura total até o início do florescimento. Para Oliveira Junior et al. (2011), as variações observadas entre as alturas de plantas das cultivares podem estar associadas à precocidade, a qual está relacionada ao ciclo vegetativo de cada cultivar.

$\mathrm{O}$ que se busca nos programas de melhoramento genético de girassol é que priorizem materiais com menor porte, pois plantas altas são mais suscetíveis ao quebramento do caule e ao acamamento, podendo refletir na produtividade da cultura. O que está de acordo com Pivetta et al. (2012), onde verificaram que plantas com alturas inferiores reduzem o risco de acamamento e consequentes perdas econômicas.

Os valores médios para o tamanho do capítulo (TC) podem ser encontrados na Tabela 6, onde se observa que houve diferenciação significativa para as médias das cultivares na mesma localidade, exceto em Serra Talhada, bem como houve diferenciação significativa entre as localidades.

Os melhores resultados foram obtidos para os materiais testados em Caruaru, chegando até $25,75 \mathrm{~cm}$ de diâmetro no V50070, embora não diferenciando estatisticamente de outros. Similarmente, este material também obteve o maior TC em Araripina. É bem provável que o fato de estarem entre os materiais mais tardios, foram favorecidos no aumento do TC. Em Serra Talhada, este genótipo apresentou cerca de $40 \%$ menor tamanho de capítulo que em Caruaru.

Inversamente aos resultados no FI e DM, o girassol Embrapa 122-T apresentou as menores médias do TC, fator inferido a sua precocidade, o que pode não ter contribuído para o desenvolvimento do capítulo. De maneira similar, todos os genótipos de Serra Talhada tiveram um menor desenvolvimento dos capítulos quando comparados a Araripina e Caruaru.

O desenvolvimento de capítulos, considerando seu tamanho e uniformidade, segundo Castro e Farias (2005), pode garantir 
uma maior proporção de aquênios grandes e mais pesados, o que concorrerá para maiores índices de rendimento. Quanto maior o tamanho do capítulo, maior será seu peso hectolítrico, ou seja, peso específico de sementes (AMORIM et al., 2008). Esse componente de produção é de grande importância na comparação de cultivares de girassol, por apresentar associação positiva com a produtividade de aquênios (PIVETTA et al., 2012).

Na Tabela 7 encontra-se a média da variável peso de mil aquênios (PMA), onde se verifica que houve efeito significativo entre as cultivares nas localidades Araripina e Caruaru na comparação de médias pelo teste de Tukey a $(\mathrm{p}<0,05)$, enquanto entre as localidades as cultivares se comportaram de maneira semelhante.

Os melhores resultados foram obtidos em Caruaru, os quais seguiram o mesmo comportamento da variável anterior, ou seja, um maior TC favoreceu o crescimento dos aquênios e, consequentemente, maior peso.

O genótipo Triton Max, que teve o segundo menor TC em Araripina, possivelmente contribuiu para o menor PMA, cujo peso foi em média 30,2\% inferior ao Embrapa 122-T. Já em Serra Talhada, o menor PMA foi do V50070 inferior 29,7\% ao M 743-T, mesmo não diferenciando estatisticamente, assim como ocorreu no TC.

O peso de aquênio representa a capacidade que a planta tem de suprir nutrientes até o limite potencial estabelecido para cada cultivar (BISCARO et al., 2008), possuindo grande importância para a composição final do rendimento da lavoura de girassol, uma vez que valores significativos desse parâmetro resultam em maiores produções (CASTRO et al., 2002).

Indispensável para o estudo, os resultados da produtividade estão dispostos na Tabela 8 , onde os materiais diferiram estatisticamente dentro das localidades, exceto Serra Talhada, havendo também efeito significativo entre as localidades.

A maior produtividade foi determinada em Araripina, com 2.180,00 kg.ha-1 no genótipo Embrapa 122-T, superior ao valor encontrado por Bezerra et al. (2014) no Ceará, que foi 1.516,57 kg.ha-1 com o mesmo material. De maneira geral, as médias das produtividades foram de 1.724,88, 1.501,89 e 1.851,56 kg.ha-1

Tabela 7. Médias do Peso de Mil Aquênios (PMA) de genótipos de girassol, cultivados em diferentes localidades no Estado de Pernambuco, 2011.

\begin{tabular}{|c|c|c|c|}
\hline \multirow{2}{*}{ GENÓTIPOS } & \multicolumn{3}{|c|}{ Peso de Mil Aquênios (g) } \\
\hline & Araripina & Caruaru & Serra Talhada \\
\hline 1 - M 734-T & 71,38ab A & $92,70 \mathrm{a} \mathrm{A}$ & $82,50 a \mathrm{~A}$ \\
\hline 2 - Embrapa 122 -T & 72,13a A & $83,15 a b$ A & $81,50 a \mathrm{~A}$ \\
\hline 3 - Aromo 10 & 59,80abc A & $79,18 a b \mathrm{~A}$ & $68,25 a \mathrm{~A}$ \\
\hline 4 - Paraiso 22 & $54,75 b c \mathrm{~A}$ & $68,05 b \mathrm{~A}$ & $66,50 \mathrm{a} A$ \\
\hline 5 - Albisol 20 CL & 61,30abc A & 77,03ab A & $74,25 \mathrm{a} A$ \\
\hline 6 - NTO 2.0 & 67,85ab A & $84,23 \mathrm{ab} A$ & $75,00 \mathrm{a} A$ \\
\hline 7 - Multissol & 72,08a A & $80,85 a b$ A & $75,25 \mathrm{a} \mathrm{A}$ \\
\hline 8 - V50070 & 66,08abc A & 72,90b A & 58,00 a A \\
\hline 9 - Triton max & 50,35 c A & 72,58b A & $64,25 \mathrm{a} A$ \\
\hline 10 - BRS Gira 27 & 63,05abc A & $83,35 a b$ A & $76,75 a \mathrm{~A}$ \\
\hline
\end{tabular}

Médias seguidas pela mesma letra minúscula nas colunas e maiúsculas nas linhas não diferem as cultivares dentro da localidade e entre as localidades, respectivamente, pelo teste de Tukey ao nível de 5\% de probabilidade.

Tabela 8. Médias da Produtividade (Prod) de genótipos de girassol, cultivados em diferentes localidades no Estado de Pernambuco, 2011.

\begin{tabular}{|c|c|c|c|}
\hline \multirow{2}{*}{ GENÓTIPOS } & \multicolumn{3}{|c|}{ Produtividade (kg.ha $\left.{ }^{-1}\right)$} \\
\hline & Araripina & Caruaru & Serra Talhada \\
\hline 1 - M 734-T & $1281,3 b \mathrm{~A}$ & $1596,0 a b \mathrm{~A}$ & $1610,1 \mathrm{a} \mathrm{A}$ \\
\hline 2 - Embrapa 122 -T & 2180,0a A & 1059,0b B & $1906,6 a \mathrm{~A}$ \\
\hline 3 - Aromo 10 & 1547,5ab A & $1463,8 a b \mathrm{~A}$ & $1936,9 a \mathrm{~A}$ \\
\hline 4 - Paraiso 22 & 1937,5ab A & $1618,4 a b A$ & $1622,1 \mathrm{a} \mathrm{A}$ \\
\hline 5 - Albisol 20 CL & 1180,0b B & $1218,7 a b$ B & $1821,5 a \mathrm{~A}$ \\
\hline 6 - NTO 2.0 & $1677,5 \mathrm{ab} \mathrm{A}$ & $1707,7 \mathbf{a b} \mathrm{A}$ & $1974,4 a \mathrm{~A}$ \\
\hline 7 - Multissol & $1855,0 a b \mathrm{~A}$ & $1960,4 a A$ & 2048,1a A \\
\hline 8 - V50070 & 1705,0ab A & $1830,7 \mathrm{a} A$ & $1986,4 a \mathrm{~A}$ \\
\hline 9 - Triton max & $1825,0 a b \mathrm{~A}$ & 1263,3ab B & 1847,0a A \\
\hline 10 - BRS Gira 27 & $2060,0 \mathrm{a} A$ & $1300,9 a b \mathrm{~B}$ & $1762,5 a \mathrm{AB}$ \\
\hline
\end{tabular}

Médias seguidas pela mesma letra minúscula nas colunas e maiúsculas nas linhas não diferem as cultivares dentro da localidade e entre as localidades, respectivamente, pelo teste de Tukey ao nível de $5 \%$ de probabilidade. 
para Araripina, Caruaru e Serra Talhada, respectivamente. Estes valores representam uma boa produtividade, se levarmos em consideração o cultivo em condições de sequeiro. Os materiais Multissol e V50070 mantiveram uma boa média de produtividade nas três localidades, embora outros materiais tenham se destacado especificamente em cada região.

A cultura do girassol apresenta produtividade média nacional de 1.531,0 kg.ha-1 (CONAB, 2018), porém, se adequadamente manejada, a produtividade pode elevar-se para 1.800 a $2.200 \mathrm{~kg} \mathrm{ha}^{-1}$ (HECKLER, 2002; PORTO et al., 2007; BACKES et al., 2008). Sob irrigação, a produtividade de grãos está geralmente compreendida entre valores de 2.200 a $3.000 \mathrm{~kg} \mathrm{ha}^{-1}$ (SMIDERLE et al., 2005; SILVA et al., 2007; BISCARO et al., 2008), embora existam registros de produtividade de grãos de girassol sob irrigação acima de 4.000 kg.ha-1 (KARAM et al., 2007; ANASTASI et al., 2010).

Analisando dentro de cada localidade, o girassol Embrapa 122-T foi o mais produtivo em Araripina, como mencionado, porém foi o menos produtivo em Caruaru. Nos dois casos, outros materiais não diferiram estatisticamente deste. Verificam-se variações de produtividade com $1.000 \mathrm{~kg}$ acima em Araripina em relação ao girassol M 734-T e 900 kg abaixo em relação ao Multissol para Caruaru, comparando-se ao girassol Embrapa 122-T. Em Serra Talhada, os girassóis mantiveram os valores médios para a produtividade com uma menor amplitude, onde o M 734-T ficou em torno de $440 \mathrm{~kg}$ abaixo do valor máximo.

\section{Conclusões}

- Os materiais avaliados obtiveram bom desempenho, com precipitações em torno de $550 \mathrm{~mm}$, indicando o girassol como uma boa opção de cultivo para a região Semiárida de Pernambuco;

- Os genótipos de girassol completaram o seu ciclo fisiológico mais precocemente no clima Semiárido, demonstrando mecanismos de defesa das plantas ao ambiente;

- A produtividade média em torno de $1.700 \mathrm{~kg} \cdot \mathrm{ha}^{-1}$ nas regiões do Sertão do Araripe, Pajeú e Agreste Central do Estado de Pernambuco mostrou ser favorável ao cultivo do girassol Multissol e V50070.

\section{Agradecimentos}

À Embrapa Soja pela cessão de sementes para os ensaios, e ao IPA pela disponibilização do trabalho de pesquisa agronômica.

\section{Referências}

AMORIM, E. P. et al. Correlações e análises de trilha em girassol. Bragantia, Campinas, v. 67, n. 2, p. 307-316, 2008.

ANASTASI, U. et al. Yield performance and grain lipid composition of standard and oleic sunflower as affected by water supply. Field Crops Research, Amsterdam, v. 119, p. 145-153, 2010.
ANDRADE, W. C. et al. Desempenho de diferentes cultivares de girassol no perímetro irrigado de São Gonçalo, município de Sousa-PB. Enciclopédia Biosfera, Goiânia, vol. 7, n. 12, 2011.

AQUINO, L. A.; SILVA, F. D. B.; BERGER, P. G. Características agronômicas e o estado nutricional de cultivares de girassol irrigado. Revista Brasileira de Engenharia Agrícola e Ambiental, Campina Grande, v. 17, n. 5, p. 551-557, 2013.

BACKES, R. L. et al. Desempenho de cultivares de girassol em duas épocas de plantio safrinha no Planalto Norte Catarinense. Scientia Agraria, Curitiba, v. 9, p. 41-48, 2008.

BEZERRA, F. T. C. et al. Comportamento vegetativo e produtividade de girassol em função do arranjo espacial das plantas. Revista Ciência Agronômica, Fortaleza, v. 45, n. 2, p. 335-343, 2014.

BISCARO, G. A. et al. Adubação nitrogenada em cobertura no girassol irrigado nas condições de Cassilândia - MS. Ciência e Agrotecnologia, Lavras, v. 32, n. 5, p. 1366-1373, 2008.

CANTERI, M. G. et al. SASM - Agri: Sistema para análise e separação de médias em experimentos agrícolas pelos métodos Scoft - Knott, Tukey e Duncan. Revista Brasileira de Agrocomputação, Ponta Grossa, v. 1, n. 2, p. 18-24, 2001.

CARVALHO, C. G. P. Adaptabilidade e estabilidade de genótipos de girassol resistentes a imidazolinonas em cultivos de segunda safra. Revista Brasileira de Ciências Agrárias, Recife, v. 10, n. 1, p. 1-7, 2015.

CASTRO, C.; BRIGHENTI, A. M.; OLIVEIRA JÚNIOR, A. Mistura em tanque de boro e herbicidas em semeadura convencional de girassol. Planta Daninha, Viçosa, v. 20, p. 83-91, 2002.

CASTRO, C.; FARIAS, J. R. B. Ecofisiologia do girassol. In: Leite, R. M. V. B.; Brighenti, A. M.; Castro, C. (Ed.). Girassol no Brasil. Londrina: Embrapa Soja, 2005. p.163-218.

CAVAlCANTE, F. S. et al. Desempenho Agronômico de Quatro Variedades de Girassol no Sertão Pernambucano. In: CONGRESSO BRASILEIRO DE MAMONA, 4., SIMPÓSIO INTERNACIONAL DE OLEAGINOSAS ENERGÉTICAS, 1., 2010, João Pessoa. Anais... Campina grande: Embrapa Algodão, 2010. p. 1299-1304.

COMPANHIA NACIONAL DE ABASTECIMENTO - CONAB. Acompanhamento da safra brasileira de grãos. v. 1, n. 2. Brasília: Conab, 2013.

COMPANHIA NACIONAL DE ABASTECIMENTO - CONAB. Acompanhamento da safra brasileira de grãos. Julho/18. v. 5, n. 10. Brasília: Conab, 2018.

FAGUNDES, J. D. et al. Crescimento, desenvolvimento e retardamento da senescência foliar em girassol de vaso (Helianthus annus, L.): fontes e doses de nitrogênio. Ciência Rural, Santa Maria, v. 37, n. 4, p. 987-993, 2007.

GAZZOLA, A.; FERREIRA JUNIOR, C. T. G.; CUNHA, D. A. et al. A Cultura do Girassol. Piracicaba: USP, 2012. 69 p.

HECKLER, J. C. Sorgo e girassol no outono-inverno, em sistema plantio direto, no Mato Grosso do Sul, Brasil. Ciência Rural, Santa Maria, v. 32, p. 517-520, 2002.

KARAM, F. et al. Evapotranspiration, seed yield and water use efficiency of drip irrigated sunflower under full and deficit irrigation conditions. Agricultural Water Management, Amsterdam, v. 90, p. 213-223, 2007.

JUNIOR, E. G. C. et al. Necessidade hídrica da cultura do girassol irrigado na chapada do Apodi. Revista Brasileira de Engenharia Agrícola e Ambiental, Campina Grande, v. 17, n. 3, p. 261-267, 2013.

MENEZES, V. M. M. et al. Estabilidade de cultivares de girassol de ensaio final de primeiro ano no nordeste brasileiro: Safra 2010. 
In: REUNIÃO NACIONAL DE PESQUISA DO GIRASSOL, 19. SIMPÓSIO NACIONAL SOBRE A CULTURA DO GIRASSOL, 7., 2011, Aracaju. Anais... Aracaju: Embrapa Tabuleiros Costeiros, 2011, p. 273-276.

MERRIEN, A.; MILAN, M. J. Phyiologie du Tournesol. Paris: Centre Technique Interprofessionnel des Oléagineux Metropolitáins, 1992. p. 21-27.

NOBRE, D. A. C. et al. Desempenho agronômico de genótipos de girassol no norte de Minas Gerais. Revista Agroambiente On-Line, Roraima, v. 6, n. 2, p. 140-147, 2012.

NOBRE, R. G. et al. Produção do girassol sob diferentes lâminas com efluentes domésticos e adubação orgânica. Revista Brasileira de Engenharia Agrícola e Ambiental, Campina Grande, v. 14, p. 747-754, 2010.

OLIVEIRA JUNIOR, I. S.; SILVA, S. M. S. S.; TAVARES, J. A. et al. Competição de genótipos de girassol no Sertão do Araripe-PE. In: REUNIÃO NACIONAL DE PESQUISA DO GIRASSOL, 18., SIMPÓSIO NACIONAL SOBRE A CULTURA DO GIRASSOL, 7.;2011, Aracaju, SE. Anais... Aracaju: Embrapa soja/Embrapa Tabuleiros Costeiros, 2011. 1 CD ROOM.

PIVETTA, L. G. et al. Avaliação de híbridos de girassol e relação entre parâmetros produtivos e qualitativos. Revista Ciência Agronômica, Fortaleza, v. 43, n. 3, p.561-568, 2012.

PORTO, W. S.; CARVALHO, C. G. P.; PINTO, R. J. B. Adaptabilidade e estabilidade como critérios para seleção de genótipos de girassol. Pesquisa Agropecuária Brasileira, Brasília, v. 42, p. 491-499, 2007.

SAENSEE, K.; MACHIKOWA, T.; MUANGSAN, N. Comparative performance of sunflower synthetic varieties under drought stress.
International Journal of Agriculture and Biology, Beijing, v. 14, n. 6, p. 929-934, 2012.

SANTOS JÚNIOR, J. A. et al. Cultivo de girassol em sistema hidropônico sob diferentes níveis de salinidade. Revista Ciência Agronômica, Fortaleza, v. 42, p. 842-849, 2011.

SILVA, M. L. O. et al. Crescimento e produtividade do girassol cultivado na entrassafra com diferentes lâminas de água. Revista Brasileira de Engenharia Agrícola e Ambiental, Campina Grande, v. 11, p. 482-488, 2007.

SILVA, S. M. S. et al. Competição de genótipos de girassol no sertão do Pajeu. In: REUNIÃO NACIONAL DE PESQUISA DO GIRASSOL, 19., SIMPÓSIO NACIONAL SOBRE A CULTURA DO GIRASSOL, 7., 2011, Aracaju. Anais... Aracaju - SE: Embrapa Tabuleiros Costeiros, 2011. p.307-309.

SILVA, S. S. Crescimento do girassol com níveis de reposição hídrica e potássica. Agropecuária Científica no Semiárido, Patos, v. 10, n. 2, p. 104-110, 2014.

SMIDERLE, O. J.; MOURÃO JÚNIOR, M.; GIANLUPPI, D. Avaliação de cultivares de girassol em savana de Roraima. Acta Amazonica, Manaus, v. 35, p. 331-336, 2005.

UNGARO, M. R. G.; NOGUEIRA, S. S. S.; NAGAI, V. Parâmetros fisiológicos, produção de aquênios e fitomassa de girassol em diferentes épocas de cultivo. Bragantia, Campinas, v. 59, n. 2, p. 205-211, 2000

Recebido: 11 out. 2017 Aprovado: 21 fev. 2019 